\title{
Interactome mapping suggests new mechanistic details underlying Alzheimer's disease
}

\author{
Montserrat Soler-López, ${ }^{1,4}$ Andreas Zanzoni, ${ }^{1,4}$ Ricart Lluís, ${ }^{1}$ Ulrich Stelzl, ${ }^{2}$ \\ and Patrick Aloy ${ }^{1,3,5}$ \\ ${ }^{1}$ Institute for Research in Biomedicine, Joint IRB-BSC Program in Computational Biology, 08028 Barcelona, Spain; \\ ${ }^{2}$ Max-Planck Institute for Molecular Genetics, 14195 Berlin, Germany; ${ }^{3}$ Institució Catalana de Recerca i Estudis Avançats \\ (ICREA), 08010 Barcelona, Spain
}

\begin{abstract}
Recent advances toward the characterization of Alzheimer's disease (AD) have permitted the identification of a dozen of genetic risk factors, although many more remain undiscovered. In parallel, works in the field of network biology have shown a strong link between protein connectivity and disease. In this manuscript, we demonstrate that AD-related genes are indeed highly interconnected and, based on this observation, we set up an interaction discovery strategy to unveil novel $A D$ causative and susceptibility genes. In total, we report 200 high-confidence protein-protein interactions between eight confirmed AD-related genes and 66 candidates. Of these, 31 are located in chromosomal regions containing susceptibility loci related to the etiology of late-onset $A D$, and 17 show dysregulated expression patterns in $A D$ patients, which makes them very good candidates for further functional studies. Interestingly, we also identified four novel direct interactions among well-characterized AD causative/susceptibility genes (i.e., APP, A2M, APOE, PSEN1, and PSEN2), which support the suggested link between plaque formation and inflammatory processes and provide insights into the intracellular regulation of APP cleavage. Finally, we contextualize the discovered relationships, integrating them with all the interaction data reported in the literature, building the most complete interactome associated to AD. This general view facilitates the analyses of global properties of the network, such as its functional modularity, and triggers many hypotheses on the molecular mechanisms implicated in AD. For instance, our analyses suggest a putative role for PDCD4 as a neuronal death regulator and ECSIT as a molecular link between oxidative stress, inflammation, and mitochondrial dysfunction in AD.
\end{abstract}

[Supplemental material is available for this article.]

\begin{abstract}
Alzheimer's disease (AD) is a devastating neurodegenerative disorder characterized neuropathologically by the extracellular accumulation of amyloid-beta $(\mathrm{A} \beta)$ plaques, and the intracellular accumulation of hyperphosphorylated tau protein in the form of neurofibrillary tangles (NFTs). Unfortunately, and despite the recent advances in characterization of the disease (Bettens et al. 2010; Querfurth and LaFerla 2010), current medical treatments for $\mathrm{AD}$ are purely symptomatic and hardly effective (Citron 2010). Thus, the complete understanding of the molecular mechanisms underlying $\mathrm{AD}$ is paramount for the development of novel therapies able to modify the biology of the disease and efficiently fight the increase of $\mathrm{AD}$ with age in our ever-increasing life expectancy.

Although highly heritable, AD is a genetically complex disorder associated with multiple genetic defects either mutational or of susceptibility, making genetic analysis difficult (Bertram and Tanzi 2008). It is well established that mutations in the genes encoding amyloid precursor protein (APP), presenilin 1 (PSEN1), and presenilin 2 (PSEN2) can lead to altered production of $A \beta$, which is sufficient to cause rare, early-onset ( $\sim 50 \mathrm{yr}$ of age) familial forms of AD (Selkoe and Podlisny 2002). However, the vast majority of disease cases are of late onset ( $>65 \mathrm{yr}$ of age), and this sporadic form of $\mathrm{AD}$ is widely believed to be influenced by a combination of genes that probably affect a variety of pathways involved in the production, aggregation, and clearance of $A \beta$ (Selkoe and Podlisny
\end{abstract}

\footnotetext{
${ }^{4}$ These authors contributed equally to this work.

${ }^{5}$ Corresponding author.

E-mail patrick.aloy@irbbarcelona.org.

Article published online before print. Article, supplemental material, and publication date are at http://www.genome.org/cgi/doi/10.1101/gr.114280.110.
}

2002). Indeed, the $\varepsilon 4$ allele of apolipoprotein $\mathrm{E}(A P O E)$ has been considered a key genetic factor to play a role in the multifactor pathogenesis of $\mathrm{AD}$ (Raber et al. 2004), which accounts for $\sim 50 \%$ of late-onset $\mathrm{AD}$. In addition, several other genetic risk factors have been identified (e.g., A2M, SERPINA3, LRP1, IL1A, TNF, ACE, BACE1, BCHE, CST3, MTHFR, GSK3B, NOS3), although their susceptibility implication in AD still remains unclear (Bertram et al. 2007). These genes probably converge on common pathogenic mechanisms that lead to disease predisposition and age of onset but, unfortunately, current strategies for genome association studies have not been able to identify candidate loci effectively, probably due to the highly complex disease traits (Bertram and Tanzi 2009).

Recent studies have shown that causative/susceptibility genes for many disease phenotypes often work together within the same biological module (Oti and Brunner 2007), be it a protein complex, a pathway, or a protein interaction sub-network, highlighting a strong link between protein connectivity and disease (Zanzoni et al. 2009; Pujol et al. 2010). Indeed, the number of interactions observed between disease-causing genes in several pathologies is often much higher than what would be expected by chance, and the discovery of unexpected relationships between apparently unrelated genes has emerged as a powerful tool for the identification of novel genes involved in complex diseases such as breast cancer (Pujana et al. 2007), Huntington (Goehler et al. 2004), schizophrenia (Camargo et al. 2007), or cerebral ataxias (Lim et al. 2006). In the particular case of $\mathrm{AD}$, computational analyses showed that the integration of genetic information with physical and functional interaction data can be useful for prioritizing candidate genes (Krauthammer et al. 2004; Chen et al. 2006; Liu et al. 2006). 
In this manuscript, we first explore whether, in the light of recent data, well-established AD-related genes are indeed highly interconnected. Based on the obtained results we set up an interaction discovery strategy to unveil and validate novel AD causative and susceptibility genes. Finally, we contextualize the discovered relationships in the global disease-associated network and formulate novel hypotheses that provide insights on the molecular mechanisms implicated in $\mathrm{AD}$.

\section{Results and Discussion}

\section{Identification of novel AD-related genes through interaction discovery experiments}

It has been described that, in complex diseases, causative and susceptibility genes tend to be highly interconnected (Oti and Brunner 2007). This observation was shown to be true for the four major causative genes identified for $\mathrm{AD}$ (Chen et al. 2006; Liu et al. 2006). Based on this observation, we included in our set all 12 wellestablished $\mathrm{AD}$ causative/susceptibility genes (Table 1), that we name "seeds," and checked the interconnectivity between them to see whether it was still significantly higher than expected. To do so, we computed the minimal distance between any pair of seed genes in the frame of the charted human interactome (see Methods). This measure, known as "shortest path length," quantifies the connectivity degree between two given nodes in a network. We found that the shortest path between seed genes is 3.2, meaning that, on average, we need roughly three links (i.e., two intermediate proteins) to physically connect any two gene products within this set. To assess the statistical significance of this figure, we compared this result to two different reference distributions: one consisting of randomly picked sets of 12 proteins in the human interaction space (RND1, average shortest path $=4.7$ ) and the second one, to avoid functional biases, composed by randomly picked disease-causing proteins belonging to different disorder classes (RND2, average shortest path $=4.9$ ). In both cases, the average distance among ADrelated genes was significantly shorter than that of the reference distributions $\left(P\right.$-value RND1 $=6.8 \times 10^{-18} ; P$-value RND2 $\left.=3.5 \times 10^{-23}\right)$, indicating that $\mathrm{AD}$ seed genes are indeed more interconnected than one would expect by chance.

We next sought to exploit this finding to reveal novel genes that could be involved to the onset or progression of $\mathrm{AD}$. This is, to identify those proteins that physically interact with $\mathrm{AD}$ seeds and that are located in susceptibility loci, as identified by genetic cross-

Table 1. Alzheimer's Disease genes

\begin{tabular}{ll}
\hline Gene symbol & \multicolumn{1}{c}{ Gene name } \\
\hline$\frac{A 2 M}{A C E}$ & Alpha-2-macroglobulin \\
$\frac{A P O E}{A P P}$ & Angiotensin-converting enzyme \\
$\frac{B L M H}{M P O}$ & Amyloid beta A4 protein \\
$\frac{N O S 3}{P A X I P 1}$ & Bleomycin hydrolase \\
$\frac{P L A U}{P S E N 1}$ & Myeloperoxidase \\
$\frac{P S E N 2}{S O R L 1}$ & Nitric oxide synthase, endothelial \\
\hline
\end{tabular}

We extracted the AD causative/susceptibility genes from the OMIM database (McKusick 2007) following the criteria illustrated in the Methods section. The genes that were tested in our work are underlined. linking experiments, or whose expression is dysregulated in $\mathrm{AD}$ patients. Accordingly, we defined an interaction discovery strategy to identify potential interactors of the already known AD-related genes (Table 1) in an adult brain (Fig. 1). From our initial list of 12 seed genes, we had to discard three (ACE, MPO, and SORL1) for which the open reading frames (ORFs) were not available. After converting the nine seeds into bait plasmids (see Methods for details), we carried out 45 yeast two-hybrid $(\mathrm{Y} 2 \mathrm{H})$ screens against an adult brain cDNA prey library (five replicates for each of the nine baits), which yielded 191 interactions between 151 distinct cDNA clones or preys. DNA sequence verification and a systematic BLAST search showed that 72 of the isolated potential interactors (i.e., preys) contained the downstream gene in frame with the GAL4 activation domain, while the remaining 119 clones showed plasmids with out-of-frame sequences or sequences from nonprotein-encoding regions, which were discarded. We retested all of the 72 positive interactions by cotransformant pairwise $\mathrm{Y} 2 \mathrm{H}$ arrays, and validated 32 of them, indicating that they were indeed specific interactions. Finally, as they were observed by two independent $\mathrm{Y} 2 \mathrm{H}$ screenings, we considered them as high-confidence interactions. Most of the identified preys interacted with a single bait, while only two were observed up to four times as independent clones interacting with three different baits (ST13 and UMPS prey genes).

Gene linkage analyses and genome-wide association studies have suggested that several chromosomal regions contain susceptibility loci involved in the etiology of late-onset Alzheimer's disease (LOAD) and familial $\mathrm{AD}$ with unknown genetic cause, confirming that additional $\mathrm{AD}$ genes remain to be identified (Lambert et al. 2006). As annotated in the Online Mendelian Inheritance in Man database (OMIM) (McKusick 2007), an association to $\mathrm{AD}$ has been demonstrated for four chromosome loci (7q36, 10q24, 19p13.2, and 20p), but very few associations have been unequivocally established with specific genes in these regions. Accordingly, to identify genes in these chromosomal loci potentially implicated in AD disease mechanisms, we decided to profit from our observation that $\mathrm{AD}$ causative and susceptibility genes tend to be physically connected. After discarding the $20 \mathrm{p}$ region, since it corresponds to an entire chromosome arm, we identified the 185 candidate genes within the three remaining loci and prioritized them according to their coexpression with known AD genes across a compendium of normal tissues and cell types. We estimated coexpression in terms of correlation coefficients computed using an expectation-maximization (EM) algorithm, and forced it to always consider all the brain related tissues to obtain the most relevant correlation for $\mathrm{AD}$ (see Fig. 1 and Methods). This procedure filtered out 60 candidate genes that did not coexpress with any of the known AD-related genes. With the aim of maximizing the use of genes suitable for $\mathrm{Y} 2 \mathrm{H}$ screens, we discarded genes annotated as transcription factors (37 in total) from the original candidate gene list, as early studies indicated that they could behave as self-activators and trigger the expression of the reporter genes in the absence of a direct interaction with the prey protein, although this observation has been recently challenged. We also rejected genes encoding proteins that were highly glycosylated (one), extracellular (five), or containing several known/predicted transmembrane regions (29), as these might fold improperly, as well as nine genes for which the ORFs were unavailable. Finally, we ended up with 2809 binary interactions to be tested involving nine seed and 44 candidate genes, with the hope of finding clusters of interacting proteins involving known and candidate genes that could unveil novel AD causative or susceptibility elements. 


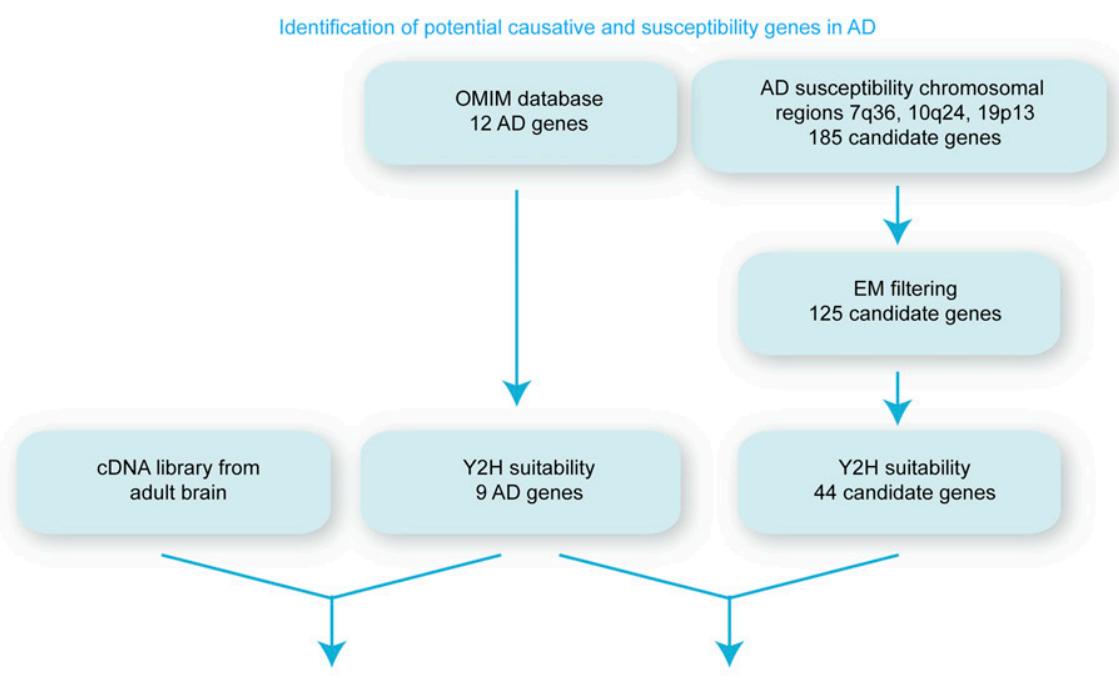

Characterization of the interactome network associated to $A D$
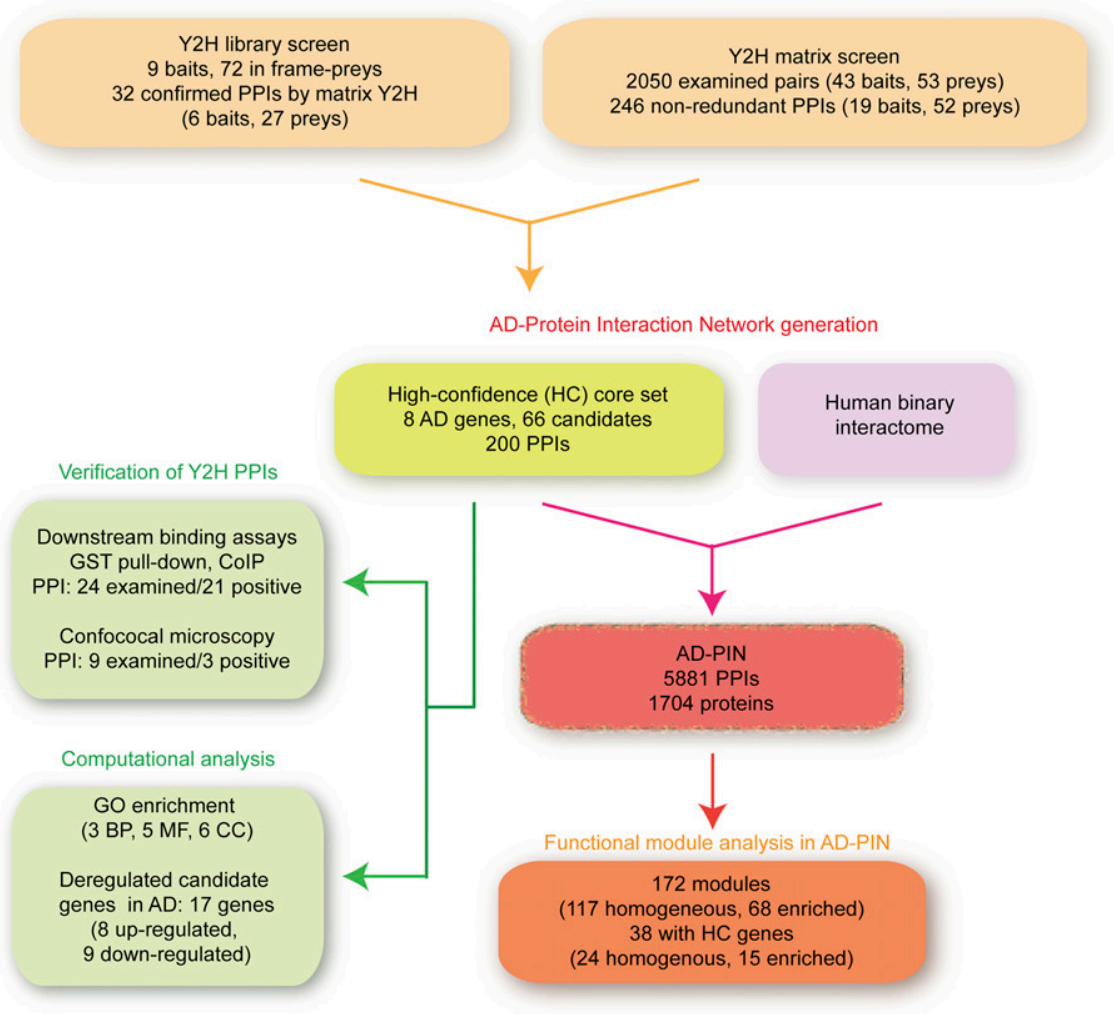

Figure 1. Flow strategy of the approach. Five major steps: (1) identification of potential and causative genes in AD; (2) characterization of the network by a Y2H screening; (3) generation of the AD protein interaction network; (4) experimental and computational assessment of the network coherence; and (5) functional module analysis of the generated AD-PIN.

We performed systematic matrix-based Y2H screens, by both cotransformation and mating approaches, to test pairwise interactions between seed and candidate genes (seed-seed, seedcandidate, and candidate-candidate combinations). We generated 53 preys (nine seeds and 44 candidates) and 43 baits (nine seeds and 34 candidate genes) from our gene selection list (see Methods), since we could not convert 10 of the prey vectors into baits. We excluded from the analyses six bait plasmids (one seed and five candidates) that resulted to be self-activating in the presence of empty prey clones. Out of the remaining 2050 pairwise protein interactions that we examined, we identified 246 nonredundant interactions between 19 baits and 52 prey proteins. Interestingly, we did not identify common protein-protein interactions to both matrix and library screens, revealing the advantage of performing pairwise and pool screens in parallel. All the detected interactions and putative susceptibility genes are reported in Supplemental File 1.

Based on the outcome derived from the $\mathrm{Y} 2 \mathrm{H}$ screens, we generated a highconfidence (HC) interaction core set containing all the confirmed library interactions and those matrix interactions that were able to activate at least two reporter genes, as they required a more solid transcriptional activation. The definitive HC protein-protein interaction network comprises 200 nonredundant interactions among 74 genes: eight seeds (no HC interactions found involving PLAU), 27 library-identified, and 39 matrix-verified candidates (Fig. 1). Only four of these interactions had been reported previously, three between seed proteins (A2M-APOE, A2M-APP, and APP-PSEN1) and one involving one candidate (PSEN1CDK5), meaning that the vast majority are entirely novel (Table 2 ). In addition, our screens did not recapitulate two other seed-seed interactions that had been found in other studies. This low overlap between different interactome networks is a well-known effect, and it is mainly attributed to the limited sampling of the interactome space and the detection capabilities of the different techniques (Russell and Aloy 2008; Venkatesan et al. 2009). In our case, this is particularly pronounced since we specifically chose our candidate genes to maximize the number of novel interactions added to the AD-related network and for which little interaction information was known (i.e., picking genes in susceptibility regions for which no direct proof of their implication in $\mathrm{AD}$ had been reported).

Although it is well-documented that different interaction discovery techniques are able to identify interactions of a different nature (i.e., binary/multimeric, transient/dedicated, etc.) (Venkatesan et al. 2009) we sought to validate some of our interactions derived from Y2H screens with complementary strategies previously employed in the identification of interactions involving AD proteins (Xia et al. 1997; Hughes et al. 1998). To this end, we randomly selected a subset of genes and protein interactions from our HC set, hoping that the results obtained would represent the general trends of the whole experiment (Fig. 2A). We first tested $11 \mathrm{HC}$ protein-protein interactions,

\section{Genome Research}


Table 2. Overlap between the $\mathrm{HC}$ set of interactions and those previously reported

\begin{tabular}{lccc}
\hline Interaction type & HC set & Human interactome & Common \\
\hline Seed-seed & 7 & 5 & 3 \\
Seed-candidate & 97 & 1 & 1 \\
Candidate-candidate & 96 & 0 & 0 \\
\hline
\end{tabular}

involving 11 genes, with GST pull-down assays (see Methods), and were able to validate seven positive interactions (Fig. 2B). We also tested $17 \mathrm{HC}$ interactions, involving 12 proteins, by coimmunoprecipitation (Co-IP) binding experiments in SH-SY5Y neuroblastoma cells, using specific antibodies against endogenously expressed proteins. Strikingly, all the tested interactions resulted positive, and most in the respective reverse co-IP experiment as well, hence confirming the interaction specificity (Fig. 2C). Overall, using both co-IP and GST-affinity binding methods, we could confirm 21 out of the 24 protein interactions we selected from our $\mathrm{Y} 2 \mathrm{H}$ core set, yielding a verification rate of $87 \%$. Of the four interactions analyzed by both techniques, one was positive by co-IP although negative in the pull-down assay (PSEN1CDC37), while the remaining three interactions were confirmed as positive by both methods (IFIT3-CDC37; NOS3-CDC37; PSEN1ECSIT). In addition, we also tested ten of the detected interactions that were not included in the HC set (seven in pull-downs, four in co-IPs), and we could only validate four of them. This verification rate of $40 \%$ indicates that, indeed, there are some real interactions among the 155 that we flagged as low-confidence, but in a much lower proportion than the ones contained in the HC set.

Additionally, we analyzed the in vivo colocalization of proteins involving nine HC interactions in mammalian cells, where endogenously expressed proteins were labeled by double immunofluorescence staining and visualized using confocal microscopy (see Methods). We were able to detect the colocalization of three interactions: ECSIT-PSEN2, ECSIT-APOE, and GCDH--NOS3, which were also validated by co-IP assays. Moreover, we also analyzed the subcellular distribution of the interactions by a double immunofluorescence staining of the respective partners in addition to the mitochondrial marker and, as expected, the GCDHNOS3 interactions did both present a mitochondrial localization (Fig. 2D).

While the accuracy achieved is very high (i.e., very few falsepositive interactions), the coverage is indeed low, meaning that we expect many more interactions involving the tested proteins than the ones detected in this study. It would be tempting to attribute this limited coverage to the intrinsic properties of many AD-related proteins which, due to their transmembrane or secreted nature, are experimentally difficult to handle. To check whether this was the case, we compared the number of interactions detected for each of the nine seed proteins employed (three secreted, three transmembrane, and three intracellular), and found no significant difference $(10.3,11.7$, and 10.3 interactions per protein on average, respectively), although the use of different Y2H setups specially designed to deal with transmembrane proteins might indeed increase the coverage (Snider et al. 2010). Thus, in this particular study, failure to detect interactions is likely to be the result of the high stringency applied to our $\mathrm{Y} 2 \mathrm{H}$ assays, particularly designed to minimize false-positives, although this criterion might penalize detection of some weak or transient interactions.

\section{Functional and gene expression analysis of the obtained} AD-related interactions

The first analysis that we applied to our HC set of interactions was to look for enrichment of particular functional terms as defined in the Gene Ontology (GO) database (Ashburner et al. 2000) (see Methods). In total, we identified 14 significantly enriched terms (adjusted $P$-value $<0.05)$ comprising three biological processes, five molecular functions, and six cellular component terms (see Table 3). Some of these are related to AD seed proteins (e.g., redox signaling or cytoskeletal proteins) and are consistent with current knowledge of the biological functions and compartments implicated in AD (Reddy 2009). However, more interestingly, we also found significant enrichments for certain unexpected functions or subcellular localizations that are not associated to known $\mathrm{AD}$ genes (e.g., regulation of apoptosis or actin binding activities).

We also checked whether the genes present in our HC set had been found to be related to the $\mathrm{AD}$ phenotype based on microarray data (Fig. 3; Blalock et al. 2004). In this study, Blalock and colleagues analyzed hippocampal gene expression of nine controls and 22 individuals suffering from $\mathrm{AD}$ of varying severity (incipient, moderate, and severe) and tested the correlation of each gene expression with MMSE (mini-mental status examination) and NFT (neurofibrillary tangles) scores across all 31 subjects regardless of the diagnosis (see Methods). We found that 17 of the 66 genes in our $\mathrm{HC}$ interactors are either up- or down-regulated in $\mathrm{AD}$ subjects compared to control, which represents a $25.7 \%$ of the total. This figure is comparable to the one observed for the known seed genes and their direct interactors, where 26 out of 97 genes $(26.8 \%)$ are dysregulated, and significantly higher than expected by chance when comparing the percentage with altered expression in AD within the human genome $\left(2508 / 24210 ; P\right.$-value $<3 \times 10^{-4}$ in a two-sided Fisher's test) and the genes present in the microarray employed by Blalock et al. (2004), although statistically insignificant $(2508 / 13,030 ; P$-value $<0.12)$. Curiously, the fraction of $\mathrm{AD}$ down-regulated genes in our $\mathrm{HC}$ gene set (0.53) is slightly higher than the fraction detected in the original study (0.43), but doubles the one found among the AD-related genes and interactors curated from the literature (0.23), which suggest a small bias toward the study of up-regulated genes in directed experiments ( $P$-value $<0.057$ in a two-sided Fisher's test). In any case, the discovery of direct interactions between dysregulated genes in $\mathrm{AD}$ subjects and well-characterized seeds could certainly trigger further functional studies to investigate their potential role in the disease phenotype.

Finally, we investigated whether any candidate from the HC set was listed in the AlzGene database (November 2010 download) (Bertram et al. 2007). We found that six out of the 58 genes that we identified as direct interactors of the $\mathrm{AD}$-seed proteins are present in the AlzGene database, three candidates (CYP2C8, CDK5, LIPF) and three coming from the library screens (EFEMP1, GAPDH, TCN2). In addition, there are two more (DYNC1H1, EID1) that are located next to the linked regions identified by recent GWAS experiments (Bertram and Tanzi 2009). Interestingly, none of the candidates that do not interact with seeds is present in AlzGene, which reinforces the message that the genes identified in our interaction discovery pipeline might certainly play a role in $\mathrm{AD}$.

\section{Direct interaction partners among $A D$ seed proteins}

To date, the experimental difficulties associated to the majority of $\mathrm{AD}$ proteins has resulted in a very limited number of literature reported interactions among $\mathrm{AD}$ seed proteins, a number that is 
A
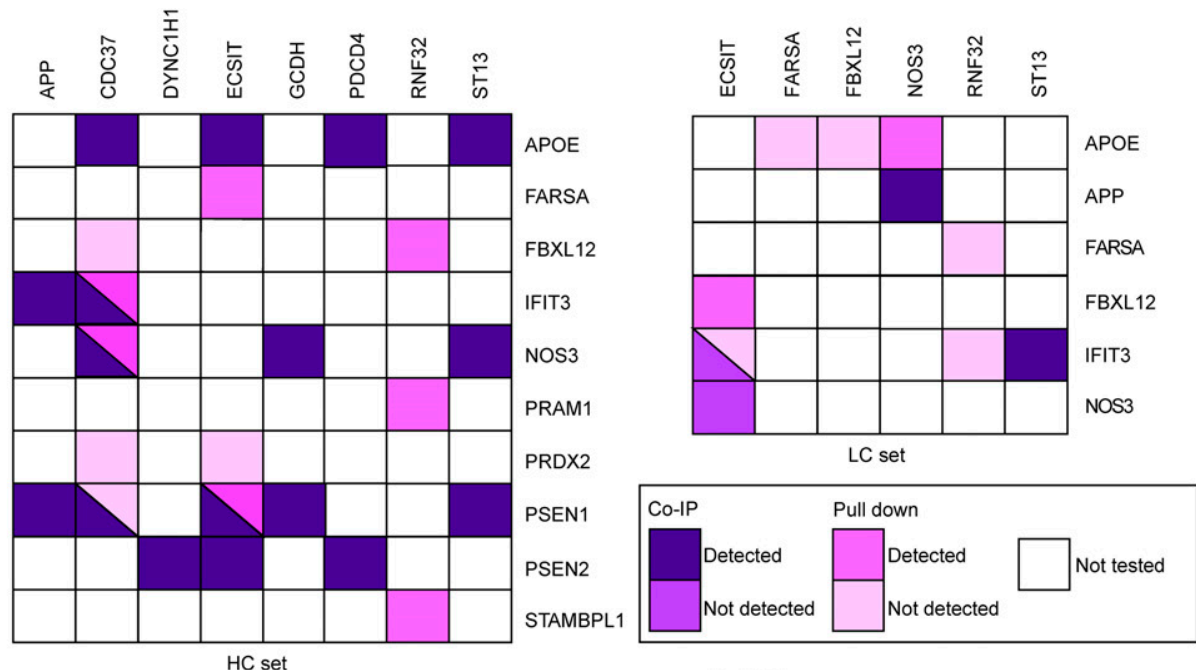

B
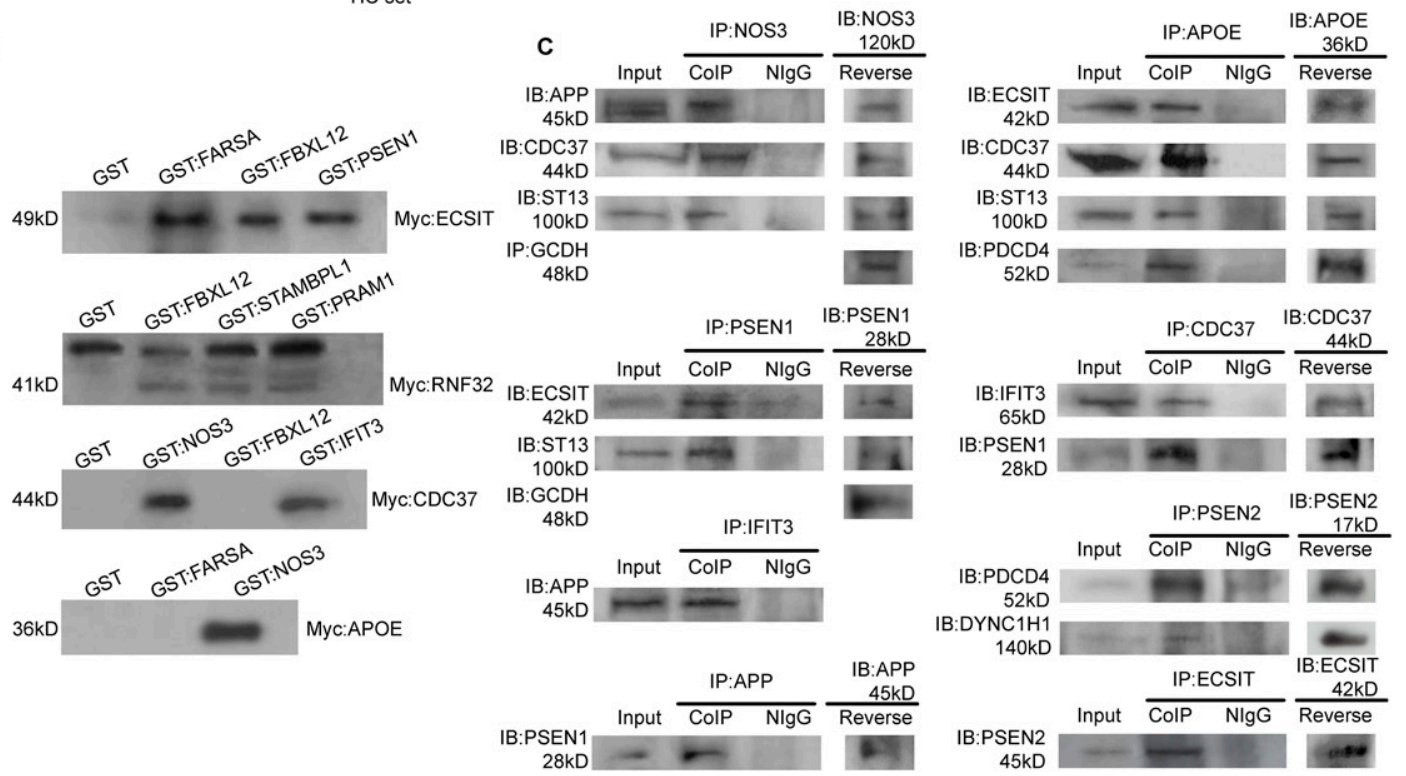

D
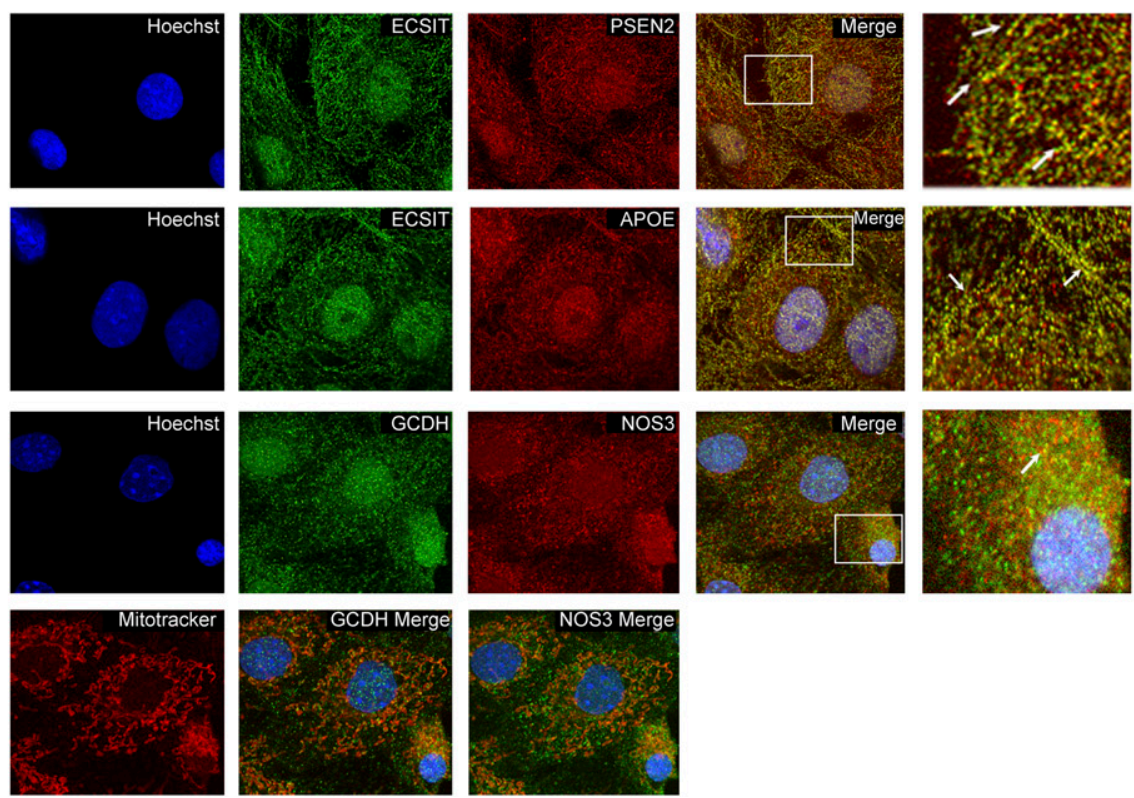

Figure 2. (Legend on next page) 
further reduced for direct interactions (Xia et al. 1997; Krimbou et al. 1998; Hesse et al. 1999). Interestingly, we identified seven direct interactions among $\mathrm{AD}$ causative genes, four of which correspond to novel interactions that might provide new insights into the molecular pathways underlying this disorder (Fig. 3). For instance, we found an interaction between alpha2macroglobulin (A2M) and APP, which corroborates the finding that $\mathrm{A} 2 \mathrm{M}$ is a strong and specific interactor of $\mathrm{A} \beta$ peptide in $\mathrm{AD}$ plasma (Mettenburg et al. 2002). But, more interestingly, we also found A2M to interact with PAXIP1, a gene that was identified by linkage and association studies as a novel locus for $\mathrm{AD}$ at $7 \mathrm{q} 36$ in a Dutch population-based sample (Rademakers et al. 2005). However, its functional role in $\mathrm{AD}$ still remains unclear, and this novel interaction with A2M can be used as a starting point for further investigations. In addition, we also detected an interaction between A2M and NOS3, found in close proximity to amyloid plaques (Probst et al. 1982), which supports the suggested link between plaque formation and inflammatory processes (Luth et al. 2001). However, the most interesting link is between APOE and PSEN1, which had not been reported to date. PSEN1 is primarily localized to the endoplasmic reticulum and it is required for efficient proteolysis of APP within their transmembrane domains. Mutations in PSEN1 increase the production of $\beta$-amyloid, strongly supporting the hypothesis that mutant PSEN1 interacts with APP in a way that enhances the intramembranous proteolysis (Vetrivel et al. 2006). Therefore, our direct evidence of APOE and PSEN1 binding could provide insights into the intracellular pathogenic role of APOE as a regulator of PSEN1 in APP cleavage. Furthermore, we also detected an interaction between PSEN1 and PSEN2, previously suggested to intimately cooperate as part of the gamma-secretase complex in APP cleavage. The direct binding of APP with both PSEN1, which we confirmed by co-IP, and PSEN2 had been previously suggested (Xia et al. 1997); however, there was not reported evidence of a direct PSEN1-PSEN2 binding (Haass and De Strooper 1999).

Collectively, these four novel interactions detected among central proteins in $\mathrm{AD}$ strengthen our initial observation that, as for other neurodegenerative disorders (Lim et al. 2006), AD causative and susceptibility proteins are, directly or indirectly, highly interconnected.

\section{Interactome network associated to $\mathrm{AD}$}

To contextualize the 200 novel AD-related interactions between 74 proteins that our study has revealed, we integrated them with all the interaction data reported in the literature to build the most complete interactome associated to $\mathrm{AD}$ with the data that is currently available (see Fig. 1 and Methods). This network view will permit the undertaking of functional analyses that reflect the global properties of the network, and not only single proteins or interactions. We thus retrieved from the databases all the proteins identified as direct interactors of the group of seeds considered in our study and merged them with our HC set of interactions, making a total of 403 interactions between 183 proteins. Additionally, we further extended this initial network to the next level (i.e., we included all the direct interactors, the initial set and the interconnections among them), obtaining a network of 5881 interactions among 1704 proteins, which we call the AD protein interaction network (AD-PIN). The general topology of the AD-PIN shows a path length of 3.7 and a characteristic node degree distribution that approximates a power law $\left(\gamma=1.65, R^{2}=0.911\right)$.

We next studied the structure of the AD-PIN to detect the presence of potential functional modules, defined as groups of proteins that are densely interconnected and that are functionally homogenous (i.e., functional annotation shared by the maximum number of module proteins). To identify these modules we used the MCL algorithm (van Dongen 2000), since it has proved to be more robust and tolerant to noise than other modules detection

Figure 2. Validation of $\mathrm{Y} 2 \mathrm{H}$ interactions by downstream binding assays. In vitro binding experiments: ( $A$ ) schematic diagrams showing the interactions examined by co-IP or pull-down experiments, for the high-confidence (HC) and low-confidence (LC) sets, respectively; ( $B$ ) by GST pull-down, blotting with anti-MYC antibody to detect the bound partner; (C) by coimmunoprecipitation (ColP), blotting with a specific antibody for the bound partner, respectively. (Input) Cell lysate, used as loading control; (IP) immunoprecipitated protein; (IB) immunoblotted protein; (NIgG) nonimmune rabbit or mouse immunoglobulins, used as negative IP controls. When using NIgG as IP agent, no precipitation lines were detected against IB antibodies, indicating that ColPs were protein-specific. Furthermore, reverse ColPs using IB antibodies as IP agents, followed by IP antibodies for blotting, led to the same results in almost all cases, hence confirming the interactions. Expected molecular weights are also indicated. $(D)$ In vivo colocalization of interacting partners by double immunofluorescence staining using confocal microscopy. (Upper panel) Double immunofluorescence confocal micrographs, labeled with a rabbit anti-ECSIT antibody and a secondary Alexa488-labeled anti-rabbit lgG (visualized in green pseudocolor), and with a mouse anti-PSEN2 visualized in red pseudocolor with a secondary Alexa568 labeled anti-mouse lgG (Invitrogen). Colocalized immunolabeling (merged window) appears as yellow staining in some areas (a framed area is also displayed in greater detail, see white arrows). Nuclei are displayed in blue by Hoechst staining. (Second panel) Double immunofluorescence of ECSIT and APOE following the same procedure. APOE was labeled with a mouse anti-APOE and an Alexa568 (visualized in red pseudocolor). (Third panel) Double immunofluorescence of GCDH labeled with a rabbit anti-GCDH and an Alexa488 (visualized in green pseudocolor), and NOS3 labeled with a mouse anti-NOS3 and an Alexa568 (visualized in red pseudocolor). (Bottom panel) Mitochondria staining with MitoTracker Deep Red stain (visualized in red pseudocolor). Merging with GCDH and NOS3 labeling, respectively, appears as yellow staining, indicating their mitochondrial localization. 


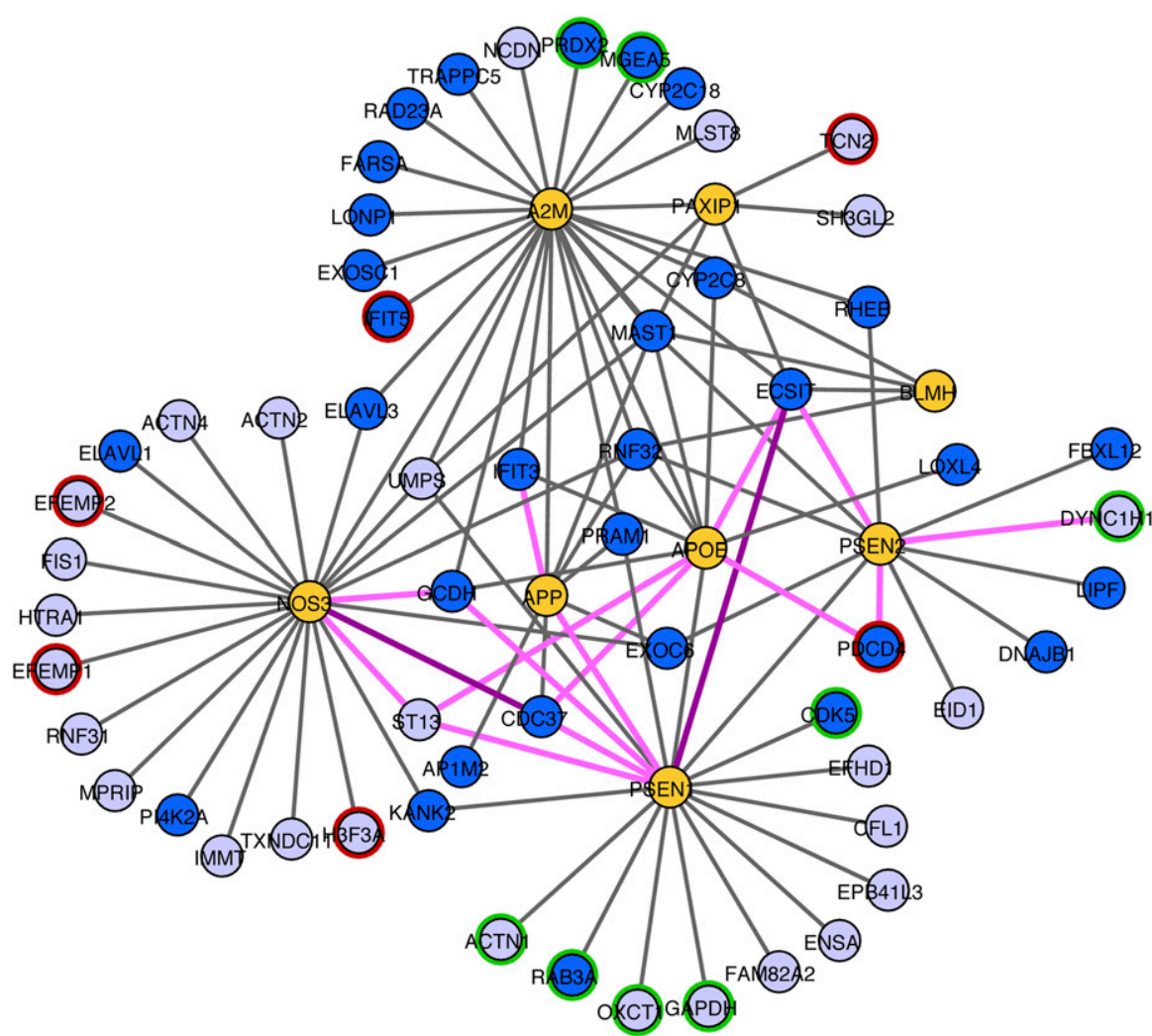

Figure 3. The $\mathrm{HC}$ interaction network. Visual representation of the relationships between $\mathrm{AD}$ seeds and $\mathrm{HC}$ interactors. Seeds are depicted in pale orange whereas $\mathrm{HC}$ matrix and library interactors are colored in dark and light blue, respectively. The AD dysregulated interactors are highlighted in red (upregulated) and green (down-regulated). Dark violet lines denote those interactions confirmed by pulldown and coimmunoprecipitation experiments, whereas lilac lines represent interactions confirmed only by coimmunoprecipitation. Candidate-candidate interactions are removed for clarity. present some of the most interesting ideas that spanned out of the novel interactions reported and the AD-PIN analyses. These potential roles are mainly sustained on literature references and would indeed need further experimental validation.

\section{Putative role of PDCD4 as neuronal death regulator in $A D$}

Amongst the most promising interactions, there are two that relate the seed proteins PSEN2 and APOE with the programmed cell death 4 (PDCD4) candidate gene (on chromosomal region 10q24), which encodes a protein localized to the nucleus under normal growth conditions, but it can also shuttle to the cytoplasm (see Fig. 2B showing the experimental validation by co-IP). It is thought to be involved in apoptosis, although the specific role has not yet been determined (Lankat-Buttgereit and Goke 2003). Expression of this gene is modulated by cytokines in natural killer and T cells, inhibiting protein translation. In addition, PDCD4 has been found to inhibit AP1-mediated transactivation and to induce expression of the cyclin-dependent kinase inhibitor p21. As a result, loss of PDCD4 confers growth advantages to the cells by several means (Talotta et al. 2009).

In the constructed AD-PIN, PDCD4 is present in a network module functionally homogeneous and enriched for "translation elongation," which is consistent methods (Brohee and van Helden 2006; Vlasblom and Wodak 2009).

With this procedure, we identified 172 modules in the ADPIN, of which 117 showed a high degree of functional homogeneity, roughly containing $55 \%$ of the proteins in the network. Additionally, we found that 68 of them were significantly enriched for one or more GO biological process annotations, the most frequent ones being related to signal transduction, transcription regulation, proteolysis, apoptosis, protein transport, and oxidative stress. If we look for the positioning of the seeds and proteins in our HC set in the AD-PIN, we find that most of them have been grouped into 38 distinct modules (69\% and 80\%, respectively), 24 of which are homogenous for, at least, one GO annotation (Fig. 4). If we compare these figures to the results obtained without including our 200 newly discovered interactions, we see that the number of clusters has risen from 146 to 172, and the number of homogeneous and enriched groups have also increased in nine and 14 modules, respectively. Perhaps more relevant to AD is the fact that the functional modules containing the seeds now include 13 new proteins, which are serious candidates to play a role in AD. All the AD-PIN modularity data is reported in Supplemental File 2.

Globally, the integration of our HC set of interactions into the larger AD-PIN, together with the analyses and visualization of the functional modules, have issued many hypotheses that might trigger novel lines of research. In the following paragraphs, we with its ability to inhibit protein translation (Yang et al. 2003). Notably, this gene is up-regulated in AD human brain tissues and thereby our observations suggest that PDCD4 could play a role in $A \beta$ neurotoxicity in conjunction with $A P O E$ and PSEN2 (see Fig. 5).

Hypothetical role of ECSIT as molecular link between oxidative stress, inflammation, and mitochondrial dysfunction in $A D$

Chronic $A \beta$ exposure increases protein oxidation in cultured neurons and in $\mathrm{AD}$ brains, indicating that mitochondria play a critical role in $\mathrm{A} \beta$ cytotoxicity and thereby in the pathogenesis of $\mathrm{AD}$ (Cumming et al. 2007). In the AD-PIN network we detected several modules linking redox signaling and immune responses. The most interesting one includes the candidate gene ECSIT (evolutionarily conserved signaling intermediate in Toll pathway), located in the susceptibility region $19 \mathrm{p} 13.2$ and presenting 13 interaction partners within the two modules (see Fig. 2 and Supplemental File 1). Based on this data, we hypothesize that ECSIT might constitute a molecular link between mitochondrial processes and AD lesions.

The ECSIT gene is an adapter protein involved in NFKB activation and also plays a role in the BMP signaling pathway required for normal embryonic development (Kopp et al. 1999). Although ECSIT acts as a cytoplasmic signaling protein in these two pathways, an N-terminal targeting signal directs ECSIT to mitochondria

\section{Genome Research www.genome.org}




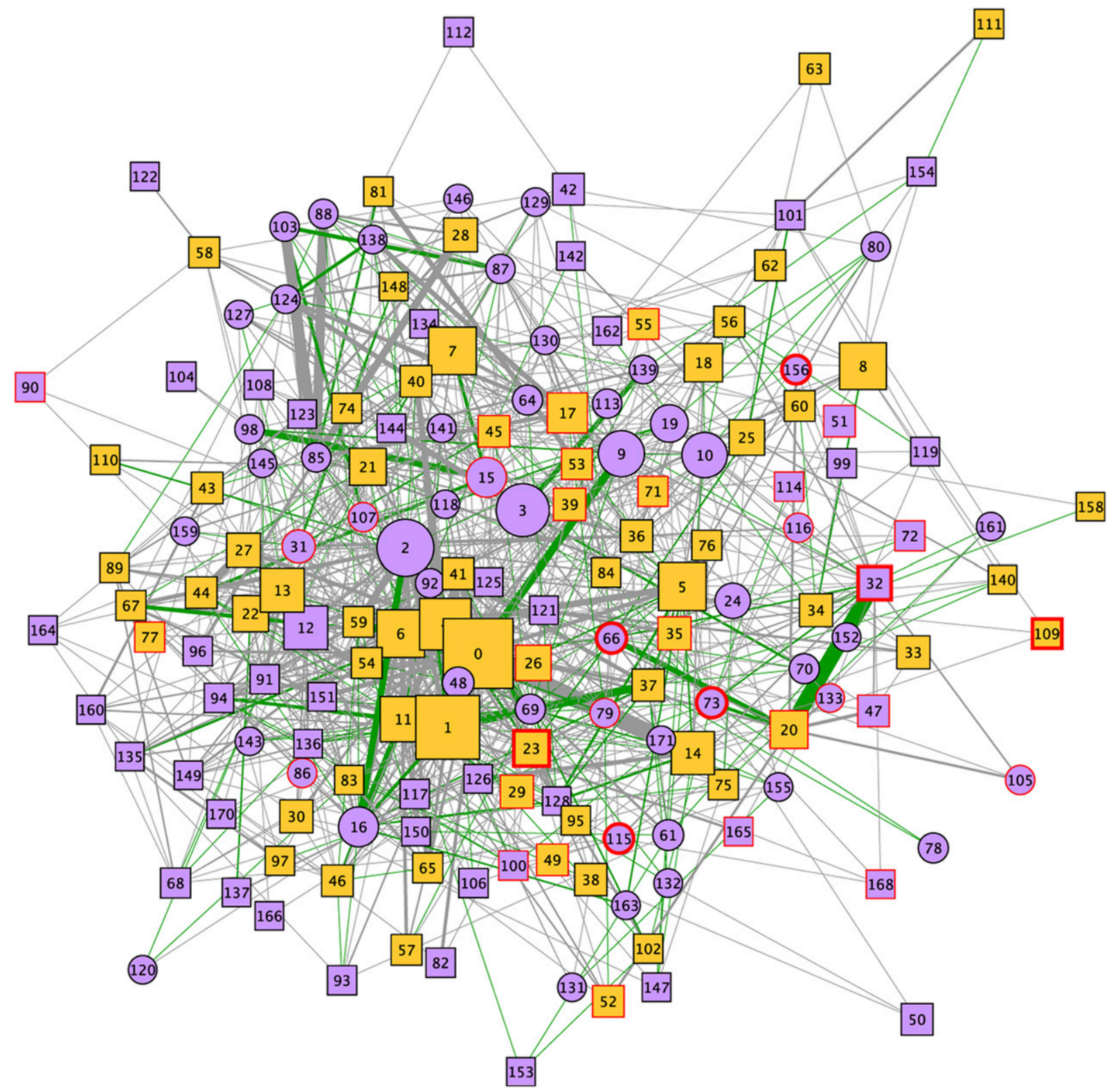

Figure 4. The modular structure of the AD-PIN. Representation of the network modules identified in the AD-PIN by the MCL algorithm. Functionally homogeneous modules are depicted as square nodes, and nonhomogeneous modules as circle nodes. Homogeneous modules that are enriched are in pale orange. Modules containing HC interactors have a thin red border, while those modules including AD seeds have a thick red one. Node labels correspond to the module identifiers provided in Supplemental File 2. The thickness of the edges is proportional to the number of interactions connecting two given clusters (max: 22; avg: 1.61; edges with at least two interactions: $257,26.96 \%)$. Green edges (20.56\% of the total, connecting 116 clusters) indicate if two clusters have at least one enriched/most abundant GO term in common.

as well (Vogel et al. 2007). In fact, cell knockdowns present a disturbed mitochondrial function that supports a role for ECSIT in linking assembly of oxidative phosphorylation complexes to inflammatory response (Vogel et al. 2007).

Our AD interaction map shows the association of ECSIT with the mitochondrial proteins Lon protease homolog (LONP1), required for intramitochondrial proteolysis as a cellular response to oxidative stress, and glutaryl-CoA dehydrogenase (GCDH), involved in redox signaling, which also interacts with the AD seed NOS3 (Fig. 2D). In addition, we observe ECSIT interactions with other endoplasmic reticulum redox proteins, like the lysyl-oxidase homolog 4 (LOXL4) and the CYP2C18 (cytochrome P450 2C18), involved in an NADPH-dependent electron transport pathway. Although an altered ECSIT gene expression has not been reported in $\mathrm{AD}$ patients to date, its expression is significantly up-regulated in Huntington's patients (Borovecki et al. 2005), and we found it to physically interact with genes altered in AD brain, namely peroxiredoxin-2 (PRDX2) and interferon-induced protein with tetratricopeptide repeats 5 (IFIT5) (see Supplemental File 1). This gives further support to the hypothesis that ECSIT might modulate the energetic requirements upon inflammatory response by regulating the rate of complex I synthesis (Vogel et al. 2007). 


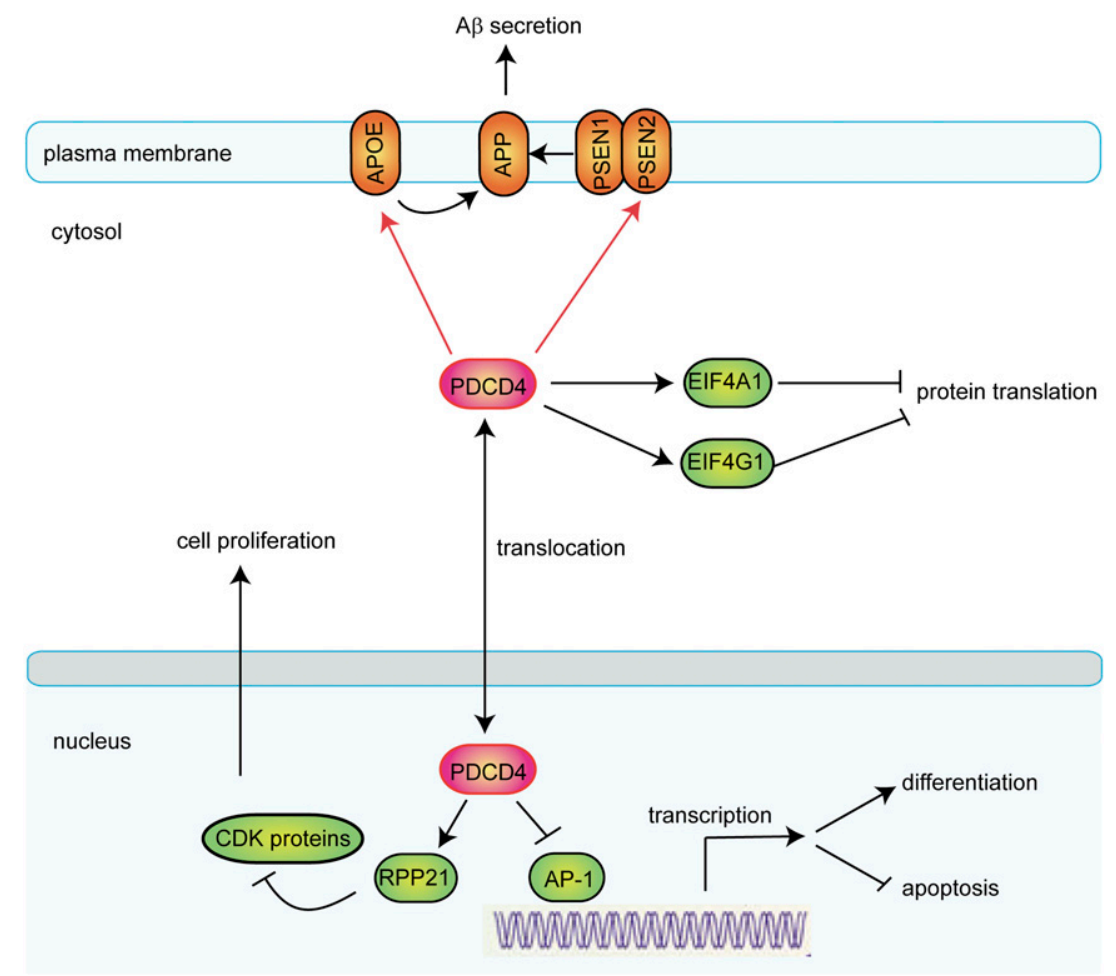

Figure 5. Putative role of PDCD4 as neuronal death regulator in $A D$. The $A D$ candidate gene PDCD4 undergoes a complex regulation by cytokines, which results in the inhibition of protein translation. This gene is up-regulated in $A D$ human brain tissues and thus the novel associations with $A D$ seeds suggest that PDCD4 could play a role in A $\beta$ neurotoxicity in conjunction with APOE and PSEN2. Literature reported interactions are depicted with black lines, while novel interactions are depicted with red lines. AD seeds are displayed as orange ellipsoids, candidates as red, and literature interactors as green ellipsoids.

Most interestingly, we observed a novel association of ECSIT with the AD gene APOE (Fig. 2C,D), which was shown to bind $A \beta$ in its oxidized form (Strittmatter et al. 1993). In $A D$ affected neurons, APOE is proteolysed and associates with neurofibrillary tangle-like structures and mitochondria, although it still remains unclear how the fragments associate and cause mitochondrial dysfunction (Nakamura et al. 2009). The physical interaction of APOE and ECSIT could thus highlight an association mechanism that would place APOE on the mitochondrial membrane for further cleavage in $\mathrm{AD}$ affected cells. The additional interactions of ECSIT with cleaving enzymes PSEN1 and PSEN2 (Fig. 2C,D) proves that ECSIT is involved in several pathways which are functionally connected, supporting the hypothesis that points ECSIT as a molecular link among oxidative stress, inflammation, and mitochondrial dysfunction in $\mathrm{AD}$ (Fig. 6).

\section{Concluding remarks}

Network and systems biology strategies offer a global perspective to explore the molecular mechanisms underlying complex diseases beyond individual genes and proteins. In this work, we have shown how a combination of interaction discovery experiments and the computational analyses of diverse biological data can provide further evidence for potential causative/susceptibility genes related to Alzheimeŕs disease, suggesting novel hypotheses as to their molecular functioning. However, to be most valuable, these functional hints coming from global analyses will need to be individually validated. The finding that causative genes are often highly interconnected, even in complex heterogeneous disorders, places network biology strategies in a privileged position to complement genome-wide association studies and next generation sequencing techniques in the quest for novel genes associated to human pathologies. We anticipate that large international efforts, such as the ongoing initiatives to chart disease-related interaction maps (Charbonnier et al. 2008), will soon permit the generation of the basic wiring inherent to most physiopathological processes and refine systems biology models to the point where they can be effectively applied to biomedicine.

\section{Methods}

\section{AD-related genes and chromosomal region selection}

We extracted all the disease-related proteins from the OMIM Morbid Map database (January 2008) and picked as AD genes those loci with the "(3)" tag, which showed evidence that at least one mutation is known to be associated with $\mathrm{AD}$ (Table 1). We then identified four chromosomal regions, namely 7q36 (MIM: 609636), 10q24 (MIM:605526), 19p13.2 (MIM:608907), and 20p (MIM:607116) for which the association with the $\mathrm{AD}$ phenotype was confirmed but that did not contain any gene directly related to $\mathrm{AD}$. We discarded the region $20 \mathrm{p}$, since it comprised the whole short arm of chromosome 20.

\section{Connectivity assessment}

We built a human interactome fetching the most recent available data (September 2009) from DIP, IntAct, and MINT databases (Salwinski et al. 2004; Aranda et al. 2010; Ceol et al. 2010). We selected experimentally verified direct interactions and added those interactions described as binary according to the associated detection methods (Rual et al. 2005). We further extended the interactome including the HPRD data set (Keshava Prasad et al. 2009), obtaining a human binary interactome consisting of 22,194 interactions between 8347 proteins.

We then evaluated the interconnectivity of $\mathrm{AD}$-related genes in terms of average shortest path length. To assess the statistical significance of the connectivity measure, we defined two reference distributions: 10,000 instances of size equal to 12 (the number of AD-related genes) consisting of randomly picked proteins from (1) the human binary interactome and (2) disease-associated proteins belonging to distinct disorder classes (Goh et al. 2007) and present in the human binary interactome. We compared the AD genes average shortest path length and the random set average shortest path length using the Mann-Whitney $U$ test.

\section{Correlation in gene expression profiles}

We used the microarray data from Su et al. (2004), a compendium of gene expression profiles from 73 normal tissue and cell types.

\section{Genome Research www.genome.org}




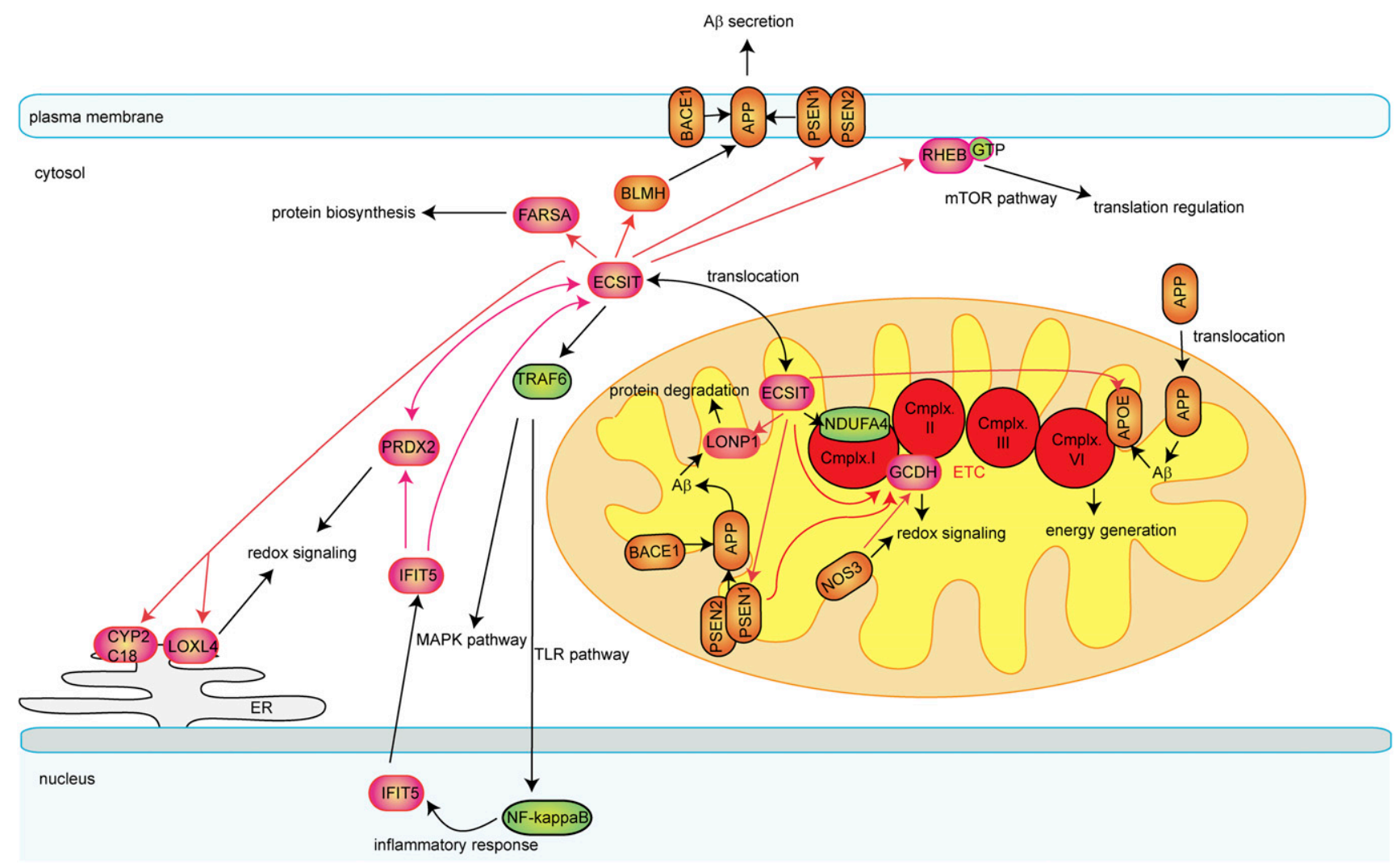

Figure 6. Potential contribution of new molecular mechanisms to mitochondrial dysfunction in AD. The AD candidate gene ECSIT, which is involved in TLR and BMP signaling pathways and also in the assembly of mitochondrial redox complexes, shows additional interactions with several AD causative and candidate genes that are functionally connected. Thus ECSIT can constitute a molecular link among oxidative stress, inflammation, and mitochondrial dysfunction in AD. Literature reported interactions are depicted with black lines, while novel interactions are depicted with red lines. AD seeds are displayed as orange ellipsoids, candidates as red, and literature interactors as green ellipsoids. (ETC) Electronic transport chain.

We applied a mixture model in order to obtain correlation coefficients that are robust under the presence of noise. We fit the model using the expectation maximization (EM) algorithm (Dempster et al. 1977). We defined two genes as coexpressed if their EM correlation coefficient was $>0.5$ and the probability of noise $<0.5$.

\section{$\mathrm{Y} 2 \mathrm{H}$ cotransformation screens}

We individually transferred the ORFs corresponding to the selected AD genes into $\mathrm{Y} 2 \mathrm{H}$ destination vectors by Gateway recombinational cloning (ProQuest System, Invitrogen Inc.). We cloned the seed genes into pDEST32 to generate bait plasmids. Seed and candidate genes were cloned into pDEST22 to obtain prey plasmids.

We pairwise cotransformed bait and prey plasmids into a MaV203 yeast strain in a 96-well array format. We plated cotransformed cells onto selective SD2 (lacking Leu and Trp amino acids) agar media and incubated them for $48 \mathrm{~h}$ at $30^{\circ} \mathrm{C}$. After a colony replica clean plating, we then replicated cotransformant arrays onto different selective media agar plates to detect colony growth. To assay the activation of the HIS3 reporter gene, SD3 (lacking Leu, Trp, His) agar plates were supplemented with 12-100 mM 3-aminotriazole (3AT, Sigma-Aldrich), $50 \mathrm{mM}$ 3AT being the optimal concentration for positive HIS 3 activation colonies. Similarly, we assayed the activation of the URA3 reporter gene by plating onto SD3 (lacking Leu, Trp, uracil) media or SD2 supplemented with 5-Fluoroorotic acid (5FOA, Sigma-Aldrich) for nega- tive colony selection. Double reporter HIS3/URA3 activation was evaluated by SD4 (lacking Leu, Trp, His, uracil) agar plates. We tested the lacZ reporter gene by the beta-galactosidase assay on a nylon membrane placed onto a SD2 agar plate.

\section{Y2H mating screens}

We individually transformed bait and prey clones into MAT $\alpha$ or MATa yeast haploid strains, respectively, in a 96-well array format. We cultured the single transformants into appropriate selective liquid medium (lacking Trp for the baits or Leu for the preys) to ensure the selection of transformants. We mated 43 MATa yeast cells individually expressing baits against 44 MAT $\alpha$ prey-expressing cells in a pairwise format. We subsequently incubated the mates onto YPD (yeast rich media) plates for $48 \mathrm{~h}$ at $30^{\circ} \mathrm{C}$. We then replated the coexpressing colonies onto SD2 (without Leu or Trp) agar medium and transferred the mated cells onto SD3 and SD4 agar plates to assess the activation of HIS 3 and URA3 reporter genes. lac $Z$ reporter gene was evaluated by a beta-galactosidase assay on a nylon membrane placed on a SD2 agar plate.

\section{Y2H library screens}

We performed a $\mathrm{Y} 2 \mathrm{H}$ library screen using an adult human brain cDNA prey library (ProQuest, Invitrogen). We transformed yeast cells expressing individual baits (generated from the seeds) with the cDNA prey library and screened them onto selective agar media 
to check HIS3 and URA3 reporter gene activation. After $7 \mathrm{~d}$ incubation at $30^{\circ} \mathrm{C}$, we picked up positive growing colonies and cultured them in prey selective liquid medium (lacking Trp). In each screen, we typically tested $6 \times 10^{4}$ auxotrophic transformants on selective plates, obtaining 1-15 positive colonies in average. We extracted the prey plasmid DNAs from the cultures and we subsequently carried out the bacterial transformation of each plasmid in order to enable DNA sequencing and subsequent gene identification by BLAST search.

We further tested the preys we identified by the library together with their respective baits in cotransformation assays for activation of reporter gene expression, in a similar procedure as explained above.

\section{In vitro pull-down assays}

For GST pull-down assays (PD), we selected genes that yielded detectable protein overexpression in COS-7 mammalian cells. As several genes encode for membrane proteins, we observed limited overexpression, which enabled us to only test 12 genes involved in 11 protein-protein interactions. We transferred each partner gene into a GST- or MYC-expression vector using the Gateway system (Invitrogen, Inc.), and transfected GST-fused plasmids into COS7 mammalian cells using Lipofectamine 2000 following the manufacturer's instructions. We cultured cells in Dulbecco's modified Eagle's medium (DMEM) supplemented with 10\% fetal bovine serum (FBS) and antibiotics (100 U/mL penicillin and $10-6 \mathrm{mg} / \mathrm{mL}$ streptomycin). All reagents were purchased from Invitrogen Inc.

Two days after transfection, we harvested and lysed cells with lysis buffer $(0.2 \% \mathrm{NP}-40,0.05 \%$ Triton X-100, $50 \mathrm{mM}$ Tris- $\mathrm{HCl}$ at $\mathrm{pH} 7.85,50 \mathrm{mM} \mathrm{NaCl}, 5 \mathrm{mM} \mathrm{MgCl} 2,50 \mu \mathrm{M} \mathrm{ZnCl}_{2}, 0.5 \mathrm{mM}$ EDTA, $10 \%$ glycerol, and complete protease inhibitor cocktail [Roche]). We cleared whole cell lysates by centrifugation for $20 \mathrm{~min}$ at $16,000 \mathrm{~g}$ at $4^{\circ} \mathrm{C}$ and we purified the soluble protein complexes using glutathione Sepharose 4B beads (GE Healthcare). We then extensively washed the beads three times with lysis buffer. We eluted and analyzed bound proteins by SDS-PAGE and Western blotting.

We detected MYC- and GST-tagged proteins using mouse antiMYC monoclonal antibody (mAb) (Invitrogen, cat. 13-2500) and rabbit polyclonal antibody (pAb) (Invitrogen, cat. 71-7500) or mouse $\mathrm{mAb}$ anti-GST (Invitrogen, cat. 13-6700).

\section{Coimmunoprecipitation (Co-IP) assays}

For co-IP assays, we selected those interactions involving proteins with both commercially available and compatible specific antibodies.

We cultured SH-SY5Y human neuroblastoma cells in DMEM plus F12 (1:1) supplemented with 10\% FBS, 2 mM sodium pyruvate, and $2 \mathrm{mM}$ nonessential amino acids (NEAA). After lysis with a mild buffer $(0.5 \%$ Triton X-100, $50 \mathrm{mM}$ HEPES at pH 7.50, $150 \mathrm{mM}$ $\mathrm{NaCl}, 1 \mathrm{mM} \mathrm{MgCl}, 1 \mathrm{mM}$ EGTA, and complete protease inhibitor cocktail [Roche]), we cleared whole cell lysates by centrifugation for $20 \mathrm{~min}$ at $16,000 \mathrm{~g}$ at $4^{\circ} \mathrm{C}$.We then precleared the lysates by adding protein A/G Sepharose beads (GE Healthcare) (10\% of the total lysate). After $30 \mathrm{~min}$ of rotation at $4^{\circ} \mathrm{C}$, we removed the beads by centrifugation at $16,000 \mathrm{~g}$ at $4^{\circ} \mathrm{C}$ for $10 \mathrm{~min}$. We added the appropriate antibody (1ug) to the lysate. After incubation for $1 \mathrm{~h}$ at $4^{\circ} \mathrm{C}$ on a rotating plate, we added $30 \mu \mathrm{L}$ of protein $\mathrm{A} / \mathrm{G}$ bead slurry and incubated under rotation at $4^{\circ} \mathrm{C}$ overnight. We collected and washed the beads extensively three times with lysis buffer, we eluted the complex and after SDS-PAGE separation, we detected the binding partner of the precipitated protein using the corresponding specific antibody.

Commercially available antibodies were mouse anti-PSEN1 mAb (cat. ab15456), mouse anti-NOS3 mAb (cat. ab2801), mouse
anti-APOE mAb (cat.ab1906), mouse anti-IFIT3 mAb (cat. ab76818), mouse anti-PSEN2 mAb (cat. ab15549), rabbit anti-APP pAb (cat.ab15272), rabbit anti-ECSIT pAb (cat. ab21288), rabbit anti-CDC37 pAb (cat. ab61773), rabbit anti-GCDH pAb (cat. ab75324), rabbit anti-PDCD4 pAb (cat. ab45124), and rabbit antiST13 pAb (cat. ab73917). We purchased those antibodies from Abcam Inc.

\section{Double immunofluorescence and confocal microscopy}

COS-7 cell monolayers were harvested at $24 \mathrm{~h}$ post-infection, fixed with $4 \%$ paraformaldehyde in phosphate buffered saline (PBS) and permeabilized in $0.1 \%(\mathrm{v} / \mathrm{v})$ Triton X-100 in PBS. Cells were blocked with 1\% BSA in PBS (PBS-BSA) and reacted with a protein specific polyclonal rabbit antibody (1:200 in PBS-BSA) and Alexa Fluor 488-labeled goat anti-rabbit IgG (Invitrogen), and a protein mouse monoclonal antibody (1:200 in PBS-BSA) and Alexa Fluor 568-labeled goat anti-mouse IgG antibody (Invitrogen). Samples were treated with Hoechst stain (Invitrogen) for nuclei staining and with MitoTracker Deep Red stain (Invitrogen) for mitochondrial staining. They were subsequently mounted on slides. Samples were analyzed using a Leica TCS SP2 confocal microscope.

\section{Gene Ontology annotation}

We used the human GO annotation extracted from the Entrez gene2go file (NCBI, September 2009) and assessed the statistical significance of GO term enrichment using the Fisher's exact test. We adjusted the $P$-values for multiple testing, applying the Bonferroni correction.

\section{Overrepresentation of AD-dysregulated genes}

We downloaded the lists of AD-dysregulated genes from the The Molecular Signatures Database (Subramanian et al. 2005; http:// www.broadinstitute.org/gsea/msigdb/). We assessed the overrepresentation of $\mathrm{AD}$-dysegulated genes in the $\mathrm{AD}$ genes interactor sets using the Fisher's exact test.

\section{Identification of functional modules within the AD-PIN}

We applied the MCL algorithm (van Dongen 2000) to identify the cluster representing putative functional modules. Since the granularity of the clustering depends on one parameter, the inflation coefficient, $I$, we ran MCL on the AD-PIN exploring a wide range of $I$ (from 0.1 to 10.0 by steps of 0.1 ).

We chose the value of $I$ that maximized the number of functionally homogenous clusters, i.e., modules, containing at least three proteins. We evaluated the functional relatedness of modules in terms of GO homogeneity (Goh et al. 2007), GH, defined as the maximum fraction of proteins in the same module that have the same GO terms from the biological process branch. For the $G H$ computation, we required that $50 \%$ of the proteins be present in the module to be annotated with at least one GO term.

We then assessed the statistical significance of each homogeneous module, comparing its $G H$ to the mean $G H$ of a reference distribution obtained by computing the $G H$ for 10,000 randomly generated sets of the same size of the module. We picked proteins for the randomization from the human binary interactome.

\section{Acknowledgments}

We thank Roland A. Pache for useful discussions, David Rossell for help implementing the EM correlation algorithm, and Guillermo Suñé for assistance with the in vitro binding assays.

\section{Genome Research}




\section{References}

Aranda B, Achuthan P, Alam-Faruque Y, Armean I, Bridge A, Derow C Feuermann M, Ghanbarian AT, Kerrien S, Khadake J, et al. 2010. The IntAct molecular interaction database in 2010. Nucleic Acids Res 38: D525-D531.

Ashburner M, Ball CA, Blake JA, Botstein D, Butler H, Cherry JM, Davis AP, Dolinski K, Dwight SS, Eppig JT, et al. 2000. Gene Ontology: Tool for the unification of biology. The Gene Ontology Consortium. Nat Genet 25: 25-29.

Bertram L, Tanzi RE. 2008. Thirty years of Alzheimer's disease genetics: The implications of systematic meta-analyses. Nat Rev Neurosci 9: 768-778.

Bertram L, Tanzi RE. 2009. Genome-wide association studies in Alzheimer's disease. Hum Mol Genet 18: R137-R145.

Bertram L, McQueen MB, Mullin K, Blacker D, Tanzi RE. 2007. Systematic meta-analyses of Alzheimer disease genetic association studies: The AlzGene database. Nat Genet 39: 17-23.

Bettens K, Sleegers K, Van Broeckhoven C. 2010. Current status on Alzheimer disease molecular genetics: from past, to present, to future. Hum Mol Genet 19: R4-R11.

Blalock EM, Geddes JW, Chen KC, Porter NM, Markesbery WR, Landfield PW. 2004. Incipient Alzheimer's disease: Microarray correlation analyses reveal major transcriptional and tumor suppressor responses. Proc Natl Acad Sci 101: 2173-2178.

Borovecki F, Lovrecic L, Zhou J, Jeong H, Then F, Rosas HD, Hersch SM, Hogarth P, Bouzou B, Jensen RV, et al. 2005. Genome-wide expression profiling of human blood reveals biomarkers for Huntington's disease. Proc Natl Acad Sci 102: 11023-11028.

Brohee S, van Helden J. 2006. Evaluation of clustering algorithms for protein-protein interaction networks. BMC Bioinformatics 7: 488. doi: 10.1186/1471-2105-7-488

Camargo LM, Collura V, Rain JC, Mizuguchi K, Hermjakob H, Kerrien S, Bonnert TP, Whiting PJ, Brandon NJ. 2007. Disrupted in Schizophrenia 1 Interactome: Evidence for the close connectivity of risk genes and a potential synaptic basis for schizophrenia. Mol Psychiatry 12: 74-86.

Ceol A, Chatr Aryamontri A, Licata L, Peluso D, Briganti L, Perfetto L, Castagnoli L, Cesareni G. 2010. MINT, the molecular interaction database: 2009 Update. Nucleic Acids Res 38: D532-D539.

Charbonnier S, Gallego O, Gavin AC. 2008. The social network of a cell: Recent advances in interactome mapping. Biotechnol Annu Rev 14: 1-28.

Chen JY, Shen C, Sivachenko AY. 2006. Mining Alzheimer disease relevant proteins from integrated protein interactome data. Pac Symp Biocomput 11: $367-378$

Citron M. 2010. Alzheimer's disease: Strategies for disease modification. Nat Rev Drug Discov 9: 387-398.

Cumming RC, Dargusch R, Fischer WH, Schubert D. 2007. Increase in expression levels and resistance to sulfhydryl oxidation of peroxiredoxin isoforms in amyloid beta-resistant nerve cells. J Biol Chem 282: 30523-30534.

Dempster A, Laird N, Rubin D. 1977. Maximum likelihood from incomplete data via the EM algorithm. J R Stat Soc Ser B Methodol 39: 1-38.

Goehler H, Lalowski M, Stelzl U, Waelter S, Stroedicke M, Worm U, Droege A, Lindenberg KS, Knoblich M, Haenig C, et al. 2004. A protein interaction network links GIT1, an enhancer of huntingtin aggregation, to Huntington's disease. Mol Cell 15: 853-865.

Goh KI, Cusick ME, Valle D, Childs B, Vidal M, Barabasi AL. 2007. The human disease network. Proc Natl Acad Sci 104: 8685-8690.

Haass C, De Strooper B. 1999. The presenilins in Alzheimer's disease-proteolysis holds the key. Science 286: 916-919.

Hesse C, Bogdanovic N, Davidsson P, Blennow K. 1999. A quantitative and immunohistochemical study on apolipoprotein $\mathrm{E}$ in brain tissue in Alzheimer's disease. Dement Geriatr Cogn Disord 10: 452-459.

Hughes SR, Khorkova O, Goyal S, Knaeblein J, Heroux J, Riedel NG Sahasrabudhe S. 1998. Alpha2-macroglobulin associates with betaamyloid peptide and prevents fibril formation. Proc Natl Acad Sci 95: $3275-3280$.

Keshava Prasad TS, Goel R, Kandasamy K, Keerthikumar S, Kumar S, Mathivanan S, Telikicherla D, Raju R, Shafreen B, Venugopal A, et al. 2009. Human Protein Reference Database-2009 update. Nucleic Acids Res 37: D767-D772.

Kopp A, Blackman RK, Duncan I. 1999. Wingless, decapentaplegic and EGF receptor signaling pathways interact to specify dorso-ventral pattern in the adult abdomen of Drosophila. Development 126: 3495-3507.

Krauthammer M, Kaufmann CA, Gilliam TC, Rzhetsky A. 2004. Molecular triangulation: Bridging linkage and molecular-network information for identifying candidate genes in Alzheimer's disease. Proc Natl Acad Sci 101: $15148-15153$.

Krimbou L, Tremblay M, Davignon J, Cohn JS. 1998. Association of apolipoprotein E with alpha2-macroglobulin in human plasma. J Lipid Res 39: 2373-2386.
Lambert JC, Bensemain F, Chapuis J, Cottel D, Amouyel P. 2006. Association study of the PIN1 gene with Alzheimer's disease. Neurosci Lett 402: 259261.

Lankat-Buttgereit B, Goke R. 2003. Programmed cell death protein 4 (pdcd4): A novel target for antineoplastic therapy? Biol Cell 95: 515-519.

Lim J, Hao T, Shaw C, Patel AJ, Szabo G, Rual JF, Fisk CJ, Li N, Smolyar A, Hill DE, et al. 2006. A protein-protein interaction network for human inherited ataxias and disorders of Purkinje cell degeneration. Cell 125: 801-814.

Liu B, Jiang T, Ma S, Zhao H, Li J, Jiang X, Zhang J. 2006. Exploring candidate genes for human brain diseases from a brain-specific gene network. Biochem Biophys Res Commun 349: 1308-1314.

Luth HJ, Holzer M, Gartner U, Staufenbiel M, Arendt T. 2001. Expression of endothelial and inducible NOS-isoforms is increased in Alzheimer's disease, in APP23 transgenic mice and after experimental brain lesion in rat: evidence for an induction by amyloid pathology. Brain Res 913: 57-67.

McKusick VA. 2007. Mendelian Inheritance in Man and its online version, OMIM. Am J Hum Genet 80: 588-604.

Mettenburg JM, Webb DJ, Gonias SL. 2002. Distinct binding sites in the structure of alpha 2-macroglobulin mediate the interaction with betaamyloid peptide and growth factors. J Biol Chem 277: 13338-13345.

Nakamura T, Watanabe A, Fujino T, Hosono T, Michikawa M. 2009. Apolipoprotein E4 (1-272) fragment is associated with mitochondrial proteins and affects mitochondrial function in neuronal cells. $\mathrm{Mol}$ Neurodegener 4: 35. doi: 10.1186/1750-1326-4-35.

Oti M, Brunner HG. 2007. The modular nature of genetic diseases. Clin Genet 71: $1-11$

Probst A, Ulrich J, Heitz PU. 1982. Senile dementia of Alzheimer type: Astroglial reaction to extracellular neurofibrillary tangles in the hippocampus. An immunocytochemical and electron-microscopic study. Acta Neuropathol 57: 75-79.

Pujana MA, Han JD, Starita LM, Stevens KN, Tewari M, Ahn JS, Rennert G, Moreno V, Kirchhoff T, Gold B, et al. 2007. Network modeling links breast cancer susceptibility and centrosome dysfunction. Nat Genet 39: 1338-1349.

Pujol A, Mosca R, Farres J, Aloy P. 2010. Unveiling the role of network and systems biology in drug discovery. Trends Pharmacol Sci 31: 115-123.

Querfurth HW, LaFerla FM. 2010. Alzheimer's disease. N Engl J Med 362: 329-344.

Raber J, Huang Y, Ashford JW. 2004. ApoE genotype accounts for the vast majority of AD risk and AD pathology. Neurobiol Aging 25: 641-650.

Rademakers R, Cruts M, Sleegers K, Dermaut B, Theuns J, Aulchenko Y, Weckx S, De Pooter T, Van den Broeck M, Corsmit E, et al. 2005. Linkage and association studies identify a novel locus for Alzheimer disease at 7q36 in a Dutch population-based sample. Am JHum Genet 77: 643-652.

Reddy PH. 2009. Amyloid beta, mitochondrial structural and functional dynamics in Alzheimer's disease. Exp Neurol 218: 286-292.

Rual JF, Venkatesan K, Hao T, Hirozane-Kishikawa T, Dricot A, Li N, Berriz GF, Gibbons FD, Dreze M, Ayivi-Guedehoussou N, et al. 2005. Towards a proteome-scale map of the human protein-protein interaction network. Nature 437: 1173-1178.

Russell RB, Aloy P. 2008. Targeting and tinkering with interaction networks. Nat Chem Biol 4: 666-673.

Salwinski L, Miller CS, Smith AJ, Pettit FK, Bowie JU, Eisenberg D. 2004. The Database of Interacting Proteins: 2004 Update. Nucleic Acids Res 32: D449-D451.

Selkoe DJ, Podlisny MB. 2002. Deciphering the genetic basis of Alzheimer's disease. Annu Rev Genomics Hum Genet 3: 67-99.

Snider J, Kittanakom S, Damjanovic D, Curak J, Wong V, Stagljar I. 2010. Detecting interactions with membrane proteins using a membrane twohybrid assay in yeast. Nat Protoc 5: 1281-1293.

Strittmatter WJ, Weisgraber KH, Huang DY, Dong LM, Salvesen GS, PericakVance M, Schmechel D, Saunders AM, Goldgaber D, Roses AD. 1993. Binding of human apolipoprotein $\mathrm{E}$ to synthetic amyloid beta peptide: isoform-specific effects and implications for late-onset Alzheimer disease. Proc Natl Acad Sci 90: 8098-8102.

Su AI, Wiltshire T, Batalov S, Lapp H, Ching KA, Block D, Zhang J, Soden R, Hayakawa M, Kreiman G, et al. 2004. A gene atlas of the mouse and human protein-encoding transcriptomes. Proc Natl Acad Sci 101: 6062 6067.

Subramanian A, Tamayo P, Mootha V, Mukherjee S, Ebert B, Gillette M, Paulovich A, Pomeroy S, Golub T, Lander E, et al. 2005. Gene set enrichment analysis: A knowledge-based approach for interpreting genome-wide expression profiles. Proc Natl Acad Sci 102: 15545-15550.

Talotta F, Cimmino A, Matarazzo MR, Casalino L, De Vita G, D'Esposito M, Di Lauro R, Verde P. 2009. An autoregulatory loop mediated by miR-21 and PDCD4 controls the AP-1 activity in RAS transformation. Oncogene 28: $73-84$.

van Dongen S. 2000. "Graph clustering by flow simulation." $\mathrm{PhD}$ thesis, University of Utrecht, Utrecht, The Netherlands. 
Soler-López et al.

Venkatesan K, Rual JF, Vazquez A, Stelzl U, Lemmens I, Hirozane-Kishikawa T, Hao T, Zenkner M, Xin X, Goh KI, et al. 2009. An empirical framework for binary interactome mapping. Nat Methods 6: 83-90.

Vetrivel KS, Zhang YW, Xu H, Thinakaran G. 2006. Pathological and physiological functions of presenilins. Mol Neurodegener 1: 4. doi: 10.1186/1750-1326-1-4.

Vlasblom J, Wodak SJ. 2009. Markov clustering versus affinity propagation for the partitioning of protein interaction graphs. BMC Bioinformatics 10: 99 . doi: 10.1186/1471-2105-10-99.

Vogel RO, Janssen RJ, van den Brand MA, Dieteren CE, Verkaart S, Koopman WJ, Willems PH, Pluk W, van den Heuvel LP, Smeitink JA, et al. 2007. Cytosolic signaling protein Ecsit also localizes to mitochondria where it interacts with chaperone NDUFAF1 and functions in complex I assembly. Genes Dev 21: 615-624.
Xia W, Zhang J, Perez R, Koo EH, Selkoe DJ. 1997. Interaction between amyloid precursor protein and presenilins in mammalian cells: Implications for the pathogenesis of Alzheimer disease. Proc Natl Acad Sci 94: 8208-8213.

Yang HS, Jansen AP, Komar AA, Zheng X, Merrick WC, Costes S, Lockett SJ Sonenberg N, Colburn NH. 2003. The transformation suppressor Pdcd4 is a novel eukaryotic translation initiation factor $4 \mathrm{~A}$ binding protein that inhibits translation. Mol Cell Biol 23: 26-37.

Zanzoni A, Soler-López M, Aloy P. 2009. A network medicine approach to human disease. FEBS Lett 583: 1759-1765.

Received August 18, 2010; accepted in revised form December 1, 2010. 


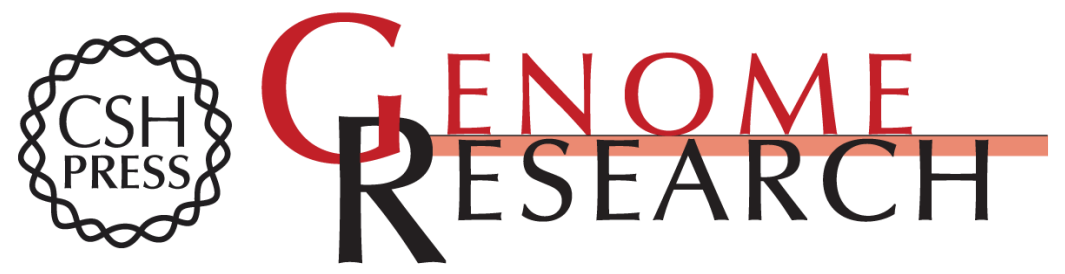

\section{Interactome mapping suggests new mechanistic details underlying Alzheimer's disease}

Montserrat Soler-López, Andreas Zanzoni, Ricart Lluís, et al.

Genome Res. 2011 21: 364-376 originally published online December 16, 2010

Access the most recent version at doi:10.1101/gr.114280.110

Supplemental Material

References

License

Email Alerting Service
http://genome.cshlp.org/content/suppl/2010/12/06/gr.114280.110.DC1

This article cites 57 articles, 16 of which can be accessed free at: http://genome.cshlp.org/content/21/3/364.full.html\#ref-list-1

Receive free email alerts when new articles cite this article - sign up in the box at the top right corner of the article or click here.

\section{Affordable, Accurate Sequencing.}

To subscribe to Genome Research go to: https://genome.cshlp.org/subscriptions 